\title{
ORCHID BIOGEOGRAPHY AND RARITY IN A BIODIVERSITY HOTSPOT: THE SOUTHWEST AUSTRALIAN FLORISTIC REGION
}

\author{
Ryan D. PhILliPS ${ }^{1,2,5}$, ANDREW P. BROWN ${ }^{3}$, KingSley W. DiXON ${ }^{1,2}$ \\ \& STEPHEN D. HOPPER ${ }^{2,4}$
${ }^{11}$ Kings Park and Botanic Garden, The Botanic Gardens and Parks Authority, West Perth, 6005, Western Australia
${ }^{2}$ School of Plant Biology, University of Western Australia, Nedlands, 6009, Western Australia ${ }^{3}$ Department of Environment and Conservation, Species and Communities Branch, Locked Bag 104, Bentley Delivery Centre, 6983, Western Australia
${ }^{4}$ Royal Botanic Gardens, Kew, Richmond, Surrey TW9 3AB, UK
${ }^{5}$ Author for correspondence: rphillips@bgpa.wa.gov.au ${ }^{1}$

KEY WORDS: pollinators, mycorrhiza, rarity, conservation, edaphic

\section{Introduction}

Understanding the drivers of orchid diversification and rarity may prove crucial to their conservation. The Orchidaceae is characterised by the presence of mycorrhizal endophytes and a diversity of pollination syndromes (Rasmussen 1995, Jersakova et al. 2006). The prevalence of pollination by deceit and the specialised mycorrhizal relationships in some taxa have been implicated in the diversification of the family (Cozzolino \& Widmer 2005, Otero \& Flanagan 2006). Furthermore, interactions with habitat specialisation may act in concert with these attributes to play a critical role in orchid diversification (Gravendeel et al. 2004). The influence of these factors in determining intrinsic rarity in orchids remains poorly known.

Delineation of biogeographic provinces and centres of species rarity give an indication of the broad-scale features responsible for restricting distributions and speciation events in plants (Stebbins \& Major 1965, Kessler 2002, Hopper \& Goia 2004). Analysis of the factors associated with rarity such as edaphic environment, pollination syndrome and site of mycorrhizal infection could reveal if any strategy has a predisposition to rarity and is limiting distribution at a more local scale. Coupling these two approaches has the potential to provide initial clues into the features influencing orchid speciation and rarity. The Orchidaceae of the South West Australian Floristic Region (SWAFR) are an ideal flora to adopt this approach because of its diversity of pollination syndromes (Hoffman \& Brown 1998), diverse mycor- rhizal infection patterns (Ramsay et al. 1986), intrinsically rare species (Brown et al. 1998) and high levels of endemism (Hopper \& Goia 2004).

Working within the SWAFR, we tested the following hypotheses (i) the pattern of orchid species richness and endemism is the same as those of the flora in general (ii) biogeographic provinces correspond to climatic and edaphic variation (iii) the incidence of rarity of species varies with site of fungal infection, pollination syndrome and habitat type. The results of this study may act as a guide to future studies of population genetics, speciation and the factors contributing to rarity in the Orchidaceae of the SWAFR.

\section{Method}

The distribution of 407 orchid taxa from southern Western Australia was mapped as presence/absence data on a grid of quarter-degree cells using the 13,267 records from the Western Australian Herbarium (PERTH) as of June 2006. Species richness for all quarter-degree grid squares was plotted on a map of southern Western Australia. A similar map of the flora of the SWAFR is presented in Hopper \& Gioa (2004). A map of the number of rare taxa per cell was also produced. UPGMA cluster analysis was used to delineate biogeographic provinces for orchids. Presence/absence of taxa at the degree grid square level was used to establish large-scale patterns, while finer resolution was achieved by repeating the analysis at the half-degree scale. Subsequently, the number of taxa endemic to each province was calculated. 
All taxa where classified by site of fungal infection, habitat preference and, where possible, pollination syndrome. Categories of fungal infection sites follow those of Ramsay et al. (1986). Species were categorised by pollination syndrome based on the published literature and field observations (A.P. Brown, unpublished data). We recognised three pollination syndromes: food reward, food deception, and sexual deception. Species that self- pollinate but also utilise one of these pollination syndromes were included within these categories. The mechanism of attraction in Corybas, Pterostylis and Rhizanthella remain unresolved so these genera were omitted from the analysis of rarity an pollination syndrome. Taxa were classified as occurring in the following habitat types: nearcoastal, granite rocks, salt lake margins, swamps, woodlands and variable. Forest, woodland and heathland species were classified together under the woodland category because these habitats usually represent a continuum caused by rainfall and are generally continuous, relatively unfragmented habitats.

We tested if site of fungal infection, pollination syndrome or habitat are associated with restricted distributions, low abundance or a high incidence of rare taxa. Using genera as replicates, Kruskal-Wallis tests were used to test for differences between pollination syndromes and sites of mycorrhizal infection in (i) the mean number of herbarium records (ii) the mean number of occupied grid squares per genus and (iii) the mean proportion of rare taxa. In Caladenia, which contains sexual and food deception, means were calculated separately for each subgenus because of multiple evolution of sexual deception (Kores et al. 2001).

\section{Results}

Species richness was highest in the High Rainfall Province, followed by the South-east Coastal Province, the Transitional Rainfall Province and the Arid Zone (nomenclature of regions follows Hopper $\&$ Goia (2004)). Nodes of exceptionally high species richness were high rainfall coastal areas with a diversity of habitats including forests, swamps and coastal woodlands and granite outcrops.

Using degree blocks, broad scale biogeographic provinces corresponded closely to those presented in
Hopper \& Goia (2004), with the exception of the Brookton province which is only evident in the Orchidaceae. The high rainfall regions and the semiarid Kalbarri sandplain had the highest level of endemism. While the high rainfall province generally contained a relatively high proportion of rare taxa, the Leeuwin-Naturaliste Ridge and parts of the southcoast had a particularly high proportion of rare species. The Kalbarri region also had an exceptionally high proportion of rare taxa.

The site of mycorrhizal infection showed no significant relationship with incidence of rarity, abundance or distributional extent. Pollination syndrome showed no significant relationship with abundance or distributional extent. However, there was significant variation in the incidence of rare taxa between pollination syndromes (sex average rank $=20.61$, food $=15.27$, reward $=10.13, \mathrm{~F}$-stat $=4.20, \mathrm{P}=0.03$ ). Using a Mann-Whitney U-test, the significant variation lied between the sexual deception and food reward pollination syndromes $(U=57.0$, d.f. $9,8, p=0.046)$.

Species with variable habitat requirements had the lowest incidence of rarity $(0.01 \%)$, woodland $(18 \%)$ and coastal $(25 \%)$ areas were intermediate, granite (46\%) and swamp (40\%) had high incidence and salt lakes $(83 \%)$ had extremely high incidence of rarity. Woodland and species of variable habitat requirements were more abundant and widely distributed than species occupying the remaining habitats.

\section{Discussion}

The Orchidaceae of the SWAFR shows a markedly different pattern of species richness to the flora in general. While the total flora is most diverse in the transitional rainfall province, the orchids have their highest diversity in coastal and lower south-west areas of the high rainfall province. Despite a different pattern of richness, orchids exhibit similar biogeographic provinces to those of the entire flora (Hopper \& Goia 2004) with boundaries delineated by rainfall and soil type. There are also clear differences in the regions of endemism. This demonstrates that while broad scale features effect species turnover of orchids in a similar way to the rest of the flora, different local process have been responsible for the accumulation of orchid species and patterns of endemism. 
Geographic region and habitat type both influence rarity in orchids of the SWAFR. Rarity was most prevalent in geographic regions with high species richness but particularly so in regions with unique edaphic environments. The naturally fragmented habitats of salt lakes, granites and swamps were most strongly associated with rare species. The prevalence of rare species from these habitats is from rarity of suitable habitat and low colonisation possibilities rather than radiation of taxa through isolation. These results demonstrate the underlying importance of edaphic environment in determining orchid rarity.

While there was no evidence from this study that site of mycorrhizal infection is linked to rarity, sexually deceptive genera showed a higher incidence of rarity than rewarding genera. This could be driven either through the greater fruit set by the provision of a reward (Neiland \& Wilcock, 1998, Jersakova \& Johnson 2006), or the specialisation associated with sexual deception leaving the orchid vulnerable to a decline in its specific pollinator. The majority of the sexually deceptive genera in the SWAFR are pollinated by parasitoid thynnine wasps (Ridsdill-Smith 1970, Stoutamire 1983), which leaves them further susceptible to changes in the abundance of the pollinator's host (Tscharntke \& Brandl 2004).

In this study we have found that there is poor congruence between areas of high species richness and endemism for orchids and angiosperms in general. Thus, in the design of conservation estate, it cannot be assumed that regions important for the flora in general will satisfy the needs of orchid conservation in terms of preserving high species richness and localised endemics. Naturally fragmented habitats are of particular importance. While granite outcrops are reasonably well protected, the other habitats remain under threat. Salt-lakes are a vulnerable habitat due to the narrow band around the lake in which orchids occur and the rising water tables resulting from the removal of over $90 \%$ of the original vegetation in the Western Australian wheatbelt (Anon. 2006). Alternatively, swamplands in the SWAFR are generally well protected in the state forests in southern Western Australia, however, the orchid rich swamps of the Swan Coastal Plain have been mostly cleared for agriculture and housing. The effects of a pronounced reduction in rainfall over recent decades $(\mathrm{Li}$ et al. 2005) remains to be seen.
In deciding management priorities for orchids, researchers should take into account the propensity towards rarity in sexually deceptive species. Due to the specificity of the plant-pollinator relationship, particular attention should be paid to the biology and requirements of the pollinator. In particular, if there are ample sites for recruitment, a direct increase in the abundance of the pollinator may lead to an increase in orchid recruitment. In the longer term, changes in the abundance of a pollinator may precede those of the orchid.

ACKNOWLedgements. Funding was provided by an Australian Postgraduate Award to RP and a grant from the Australian Orchid Foundation to RP.

\section{LITERATURE CITED}

Anonymous. 2006. State of the Environment Western Australia - Land - Theme 3. http://portal.environment.wa.gov.au/pls/portal/docs/PAGE/ADMIN_SOE/A DMIN_CONTENT/THEMES/3_LAND.PDF

Brown, A.P., C. Thomson-Dans \& N. Marchant. 1998. Western Australia's Threatened Flora. Department of Conservation and Land Management, Perth.

Cozzolino, S. \& A. Widmer. 2005. Orchid diversity: an evolutionary consequence of deception? Trends Ecol. Evol. 20 : 487-494.

Gravendeel, B., A. Smithson, F.J.W. Slik \& A. Schuiteman. 2004. Epiphytism and pollinator specialisation: drivers for orchid diversity. Philos. Trans. Royal Soc. London B 359 : 1523-1535.

Hopper, S.D. \& P. Gioia. 2004. The southwest Australian floristic region: Evolution and conservation of a global diversity hotspot. Annual Rev. Ecol. Evol. Syst. 35 : 623-50.

Jersakova, J. \& S.D. Johnson. 2006. Lack of floral nectar reduces self-pollination in a fly pollinated orchid. Oecologia $147: 60-68$.

Jersakova, J., S.D. Johnson \& P. Kindlmann. 2006. Mechanisms and evolution of deceptive pollination in orchids. Biol. Rev. 81 : 219-235.

Kessler, M. 2002. The elevational gradient of Andean plant endemism: varying influences of taxon-specific traits and topography at different taxonomic levels. J. Biogeogr 29 : 1159-1165.

Kores, P.J., M. Molvray, P.H. Weston, S.D. Hopper, A.P. Brown, K.M. Cameron \& M.W. Chase. 2001. A phylogenetic analysis of Diuridae (Orchidaceae) based on plastid DNA sequence data. Amer. J. Bot. 88 : 19031914.

Li, Y., W.J. Cai \& E.P. Campbell. 2005. Statistical modelling of extreme rainfall in Southwest Western Australia. J. Clim. 18 : 852-863. 
Neiland, M.R.M. \& C.C. Wilcock. 1998. Fruit set, nectar reward, and rarity in the Orchidaceae. Amer. J. Bot. 85 : 1657-1671.

Otero, J.T. \& N.S. Flanagan. 2006. Orchid diversity beyond deception. Trends Ecol. Evol. 21 : 64-65.

Ramsey, R.R., K.W. Dixon \& K. Sivasithamparam. 1986. Patterns of infection and endophytes associated with Western Australian orchids. Lindleyana 1 : 203-214.

Rasmussen, H.N. 1995. Terrestrial orchids from seed to mycotrophic plant. Cambridge University Press, Melbourne.
Ridsdill Smith, J. 1970. The biology of Hemithynnus hyalinatus (Hymenoptera: Tiphiidae), a parasite on scarabaeid larvae. J. Austral. Entomol. Soc. 9 : 183-195.

Stebbins, G.L. \& J. Major. 1965. Endemism and speciation in the Californian flora. Ecol. Monongr. 35 : 1-35.

Stoutamire, W.P. 1983. Wasp-pollinated species of Caladenia (Orchidaceae) in South-western Australia. Austral. J. Bot. 31 : 383-94.

Tscharntke, T. \& R. Brandl. 2004. Plant-insect interactions in fragmented landscapes. Annual Rev. Entomol. 49 : 405430 .

Ryan Phillips is a Phd student at Kings Park and Botanic Garden and the University of Western Australia working on the role of mycorrhiza and pollinators in controlling rarity and speciation in Drakaea. Interests include the causes of orchid diversification and the co-evolution of orchids and their pollinators.

Andrew Brown is an officer in the Western Australian Department of Environment and Conservation's Species and Communities Branch. He as conducted 30 years research into the taxonomy, pollination biology and genetics of the Western Australian Orchidaceae and has authored and co-authored over 70 papers, recovery plans, articles, book chapters and books on the Western Australian Orchidaceae. Current research includes the monitoring of rare orchid populations for the development of recovery prescriptions for the species.

Dr Kingsley Dixon has over 20 years experience in researching the ecology and physiology of Australian native plants and ecosystems. He leads a science group comprising botanical and restoration sciences and, as Director of Science at the Botanic Gardens and Parks Authority (BGPA), has developed a strong multi-disciplinary approach to conservation and restoration of native plant biodiversity and degraded landscapes. This research group has contributed significantly to seed science in Australia, with major advances in understanding seed dormancy as well as orchid seed conservation.

Stephen Hopper is director of the Royal Botanic Gardens, Kew. He has worked on Australian orchid systematics and conservation since 1973. Current interests include generic classification of Australian orchids, and the evolution of southwest Australian orchids. 